\title{
Suture-Less Circumcision by Glutaraldehyde Albumin Glue Enhanced Laser Tissue Welding-A Comparative Study
}

\author{
Sagar A. Jawale (1) \\ Jawale Institute of Pediatric Surgery, Jalgaon, Maharashtra, India \\ Email: drsagarjawale@gmail.com
}

How to cite this paper: Jawale, S.A. (2019) Suture-Less Circumcision by Glutaraldehyde Albumin Glue Enhanced Laser Tissue Welding-A Comparative Study. Open Journal of Urology, 9, 107-113. https://doi.org/10.4236/oju.2019.97013

Received: May 9, 2019

Accepted: July 28, 2019

Published: July 31, 2019

Copyright (อ 2019 by author(s) and Scientific Research Publishing Inc. This work is licensed under the Creative Commons Attribution International License (CC BY 4.0).

http://creativecommons.org/licenses/by/4.0/

Open Access

\begin{abstract}
Background: Suture-less circumcision by Feracrylate glue creates a weak and non waterproob bond. Hence, there is wound dehiscence and delayed healing which favor infection in many patients. I am describing a new technique for suture-less circumcision which is free from above limitations. Methods: In my center in the time span of 2 years, I did 51 cases of circumcision with Laser tissue welding technique (group A). Age range was 5 months to 21 years. During the same time span, in 56 patients circumcision was done by Feracrylate glue (group B). The age range was 3 months to 22 years. This group was kept as a control. Patients in both groups were randomly distributed. The technique of circumcision by Laser tissue welding is as follows. Patient is under short GA, the prepuce above the artery forceps is chopped off by scissors and bleeders are coagulated by bipolar cautery. Now, $0.9 \mathrm{ml} 40 \%$ human albumin is taken in $1 \mathrm{ml}$ syringe and mixed with $0.1 \mathrm{ml}$ of $10 \%$ glutaraldehyde solution. The syringe is shaken vigorously to mix both the components. The skin and mucosa of penis are held by tooth forceps and a thin layer of this mixture is layered over it all around. Infrared Laser of 5 watts power and 850 $\mathrm{nm}$ illuminated over this bond for 60 seconds to polymerize it. Results: In group A, 2 (3.9\%) patients developed partial wound gape, no patient had complete wound gape. $3(5.88 \%)$ patients had grade 2 infections which settled with conservative treatment of oral antibiotics. In group B, $6(10.71 \%)$ patients had partial wound gape and $8(14.28 \%)$ patients had complete wound gapping. 11 (19.64\%) patients developed grade 2 and 8 (14.28\%) patients grade 3 wound infection. All these 19 patients' post-operative antibiotics were started and given for 7 - 10 days. The Glutaraldehyde albumin mixture bond is already described in medical literature (Bioglue) for its use to seal coronary anastomosis after CABG operation, to seal sutures of cardiac surgery and for aortic dissection, etc. It is a surgical adhesive composed of purified bovine serum albumin (BSA) and glutaraldehyde and is already American FDA ap-
\end{abstract}


proved. It creates a flexible mechanical seal independently of the body's clotting mechanism. In my technique, $0.9 \mathrm{ml}$ of $40 \%$ human albumin is mixed with $0.1 \mathrm{ml} 10 \%$ glutaraldehyde solution which costs only 50 cents which is a massive 1000 times cost reduction. Laser application polymerizes the glue and forms a waterproob bond in less than a minute. In my technique, percentage of glutaraldehyde used is only $10 \%$ compared to $50 \%$ in bioglue, hence it is non-toxic to the tissues. Conclusion: Suture-less circumcision by glutaraldehyde albumin glue enhanced Laser tissue welding is a safe, cheap and effective technique of performing circumcision. It is an important advance in circumcision surgery after a long time. The technique becomes a foundation for its vast application in other areas of surgery.

\section{Keywords}

Circumcision, Laser Tissue Welding, Glutaraldehyde Albumin Glue, Suture-Less Circumcision

\section{Introduction}

Circumcision is the commonest operation done by a pediatric surgeon. Although the operation is centuries old, no advances have been made in the technique. Circumcision done with sutures leaves permanent and ugly marks on penis which is hated by children. The sutures keep coming out from the wound for days together. Suture-less circumcision is described with Feracrylate glue. There are many drawbacks of this technique. The bond created by this technique is weak and not waterproob. Hence, there is wound dehiscence and delayed healing which favors infection in many patients. I am describing a new technique for suture-less circumcision which is described for the first time in medical literature and is free from about limitations.

\section{Materials and Methods}

In my center in the time span of 2 years, I did 51 cases of circumcision with Laser tissue welding technique (group A). Age range was 5 months to 21 years. During the same time span, in 56 patient's circumcision was done by Feracrylate glue (group B). The age range was 3 months to 22 years. This group was kept as a control. Patients in both groups were randomly distributed as they came to the center. Patients were followed weekly for 4 weeks and monthly thereafter. Longest follow up was 2 years and shortest of 3 months.

\section{Technique of Circumcision by Laser Tissue Welding}

Patient is under short GA, the prepuce is separated from glans penis completely and the smegma cleaned. The prepuce is held by tooth forceps and an artery forceps applied transversely across the prepuce (Figure 1 and Figure 2). The prepuce above the artery forceps is chopped off by scissors. The artery forceps is 
released and bleeders are coagulated by bipolar cautery. Now, $0.9 \mathrm{ml} 40 \%$ human albumin is taken in $1 \mathrm{ml}$ syringe and mixed with $0.1 \mathrm{ml}$ of $10 \%$ glutaraldehyde solution (Figure 3 ). The syringe is shaken vigorously to mix both the components. The skin and mucosa of penis are held by tooth forceps and a thin layer of this mixture is layered over it all around. Infrared Laser of 5 watts power and 850 $\mathrm{nm}$ (Figure 4) illuminated over this bond for 60 seconds to polymerize it. No dressings are applied post operatively and patient is discharged on the same day making it a day care operation.

\section{Results}

In group A, 2 (3.9\%) patients developed partial wound-gape, no patient had complete wound gape. $3(5.88 \%)$ patients had grade 2 infections which settled with conservative treatment of oral antibiotics. The postoperative result (Figure 5 ) at the end of 6 weeks in group A was excellent cosmetically. No patient had cellulitis or allergic reaction as described with Bioglue due to glutaraldehyde toxicity. In group B, 6 (10.71\%) patients had partial wound gape and $8(14.28 \%)$ patients had complete wound gapping. 11 (19.64\%) patients developed grade 2 and $8(14.28 \%)$ patients grade 3 wound infection. All these 19 patients' postoperative antibiotics were started and given for 7 - 10 days.

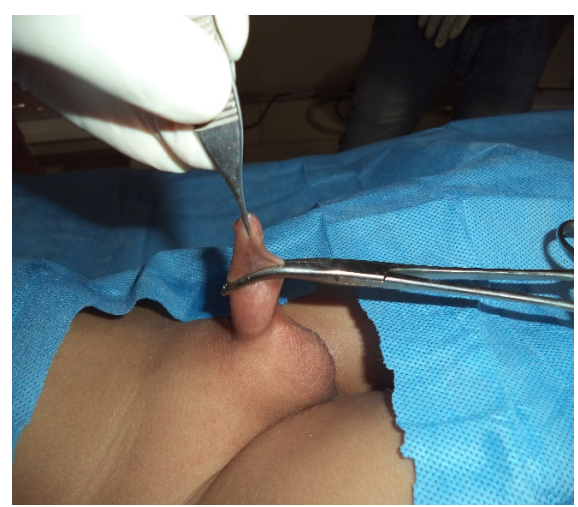

Figure 1. Technique of circumcision.

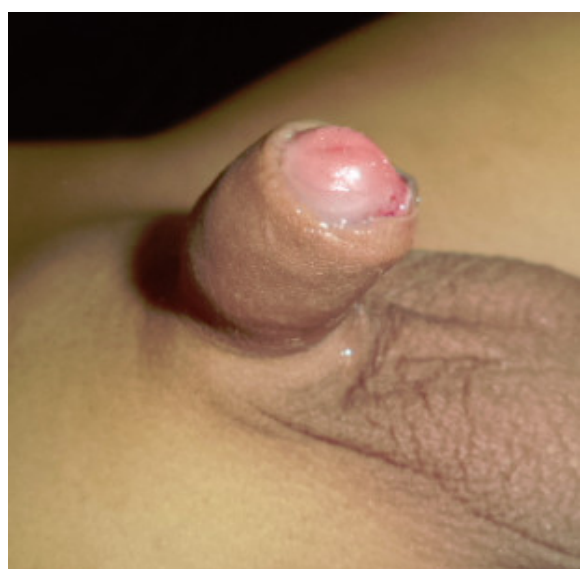

Figure 2. Penis immediately after laser tissue welding. 


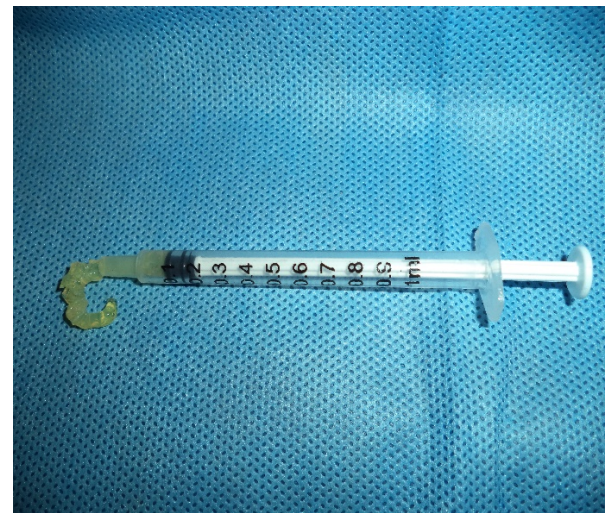

Figure 3. Syringe showing Gluteraldehyde albumin glue.

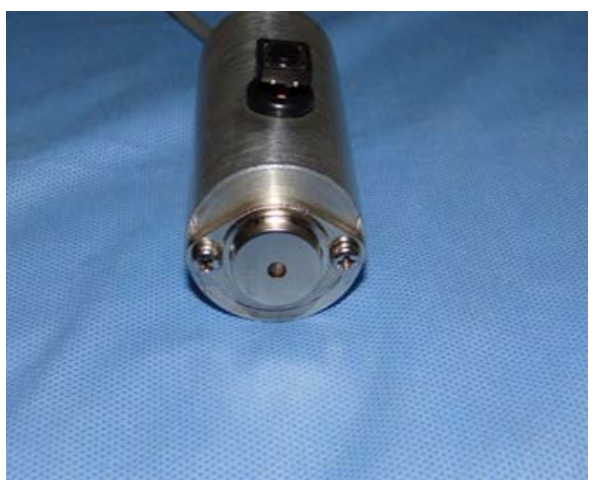

Figure 4. Laser device for tissue welding.

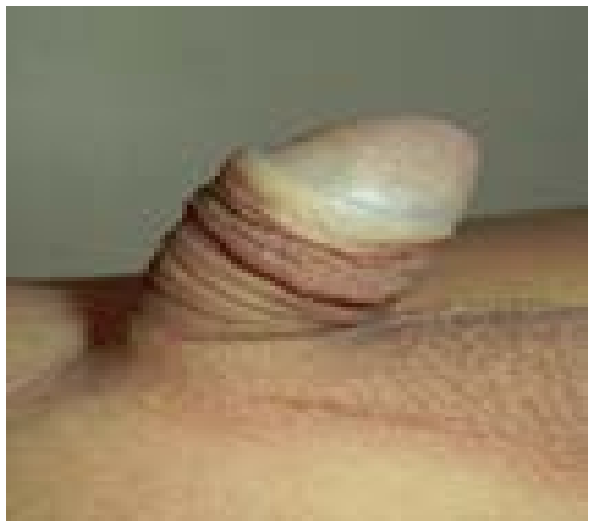

Figure 5. Penis after 6 weeks of circumcision.

\section{Discussion}

Laser tissue welding is a fantasy brought into reality [1] [2] [3]. The name tissue welding is a fancy name given to the technique looking at its similarity to welding metals together. The Glutaraldehyde albumin mixture bond is already described in medical literature in much more critical areas such as to seal coronary anastomosis after CABG operation, to seal sutures of cardiac surgery and for aortic dissection [4] [5]. It is already American FDA approved for the above purpose, hence does not raise any ethical issues to be used in other areas as cir- 
cumcision. It is available under the trade name "Bio-glue". BioGlue [4] [5] is a surgical adhesive is indicated for use as an adjunct to standard methods of achieving hemostasis (such as sutures and staples) in patients in open surgical repair of large vessels (such as aorta, femoral, and carotid arteries). BioGlue is a Surgical Adhesive which is made up of two elements such as purified bovine serum albumin (BSA) and glutaraldehyde.

Glutaraldehyde albumin mixture (Bioglue) has a predefined pre-defined ratio of 1:1 and after mixing in the applicator tip the reaction begins in 30 seconds. The glutaraldehyde molecules create a flexible mechanical seal independently of the body's clotting mechanism [4] [5]. At the repair site, glutaraldehyde molecules bond covalently (cross-link) the BSA molecules to each other and the tissue proteins. Bioglue has a tensile strength of $847 \pm 127 \mathrm{gf} / \mathrm{cm}^{2}$ and a shear strength of $256 \pm 46 \mathrm{gf} / \mathrm{cm}^{2}$ [4]. It is clinically used in more than 1.25 Million cases worldwide since 1998 . There are more than 300 pre-clinical and clinical papers on Bioglue about its safety, efficacy, and application techniques. $0.25 \mathrm{ml}$ Bio-glue costs USD 500 and it is prohibitive to be used for circumcision at least in developing countries.

In my technique, $0.9 \mathrm{ml}$ of $40 \%$ human albumin is mixed with $0.1 \mathrm{ml} 10 \%$ glutaraldehyde solution which costs only 50 cents. It is a massive 1000 times cost reduction in the cost. The mixture takes 30 minutes to dry up without Laser application and forms a weak bond. Laser application polymerizes the glue and forms a watertight bond in less than a minute (Figure 6). Higher concentration of albumin leads to a bond of higher strength [6]. Hence $40 \%$ albumin was used. In my technique, human albumin is used instead of bovine. Hence there are few chances of immunogenicity and disease transmission. The crosssection of this bond is studied under microscope. Microscopy image shows a uniform bond that has merged homogenously with the surrounding tissues [1] [3]. The thermal damage produced in surrounding tissues is negligible. Instead of sutures, the wound with this glue is held together keep millions of micro-bonds on both sides merging with tissues at molecular level making it very strong.

The laser tissue welding creates a weak bond which is not waterproob [3]. It

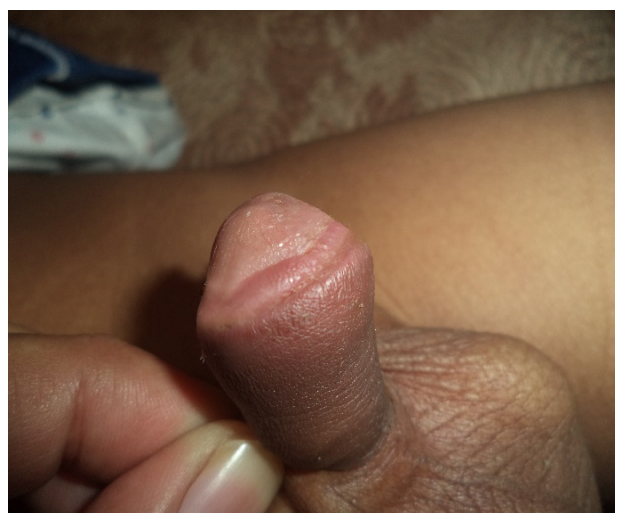

Figure 6. Penis after two weeks showing watertight bond between skin and mucosa. 
also leads to thermal damage to surrounding tissues [3] [7]. Bioglue is extremely costly and has higher concentration of glutaraldehyde (50\%). glutaraldehyde is a toxic compound and leads to a lot of side effects [4]. My technique is a combination of two techniques, one laser tissue welding with albumin and another glutaraldehyde albumin glue. It has the advantages of both techniques without having their disadvantages. In my technique, percentage of glutaraldehyde used is only $10 \%$ compared to $50 \%$ in bioglue. Hence it is non-toxic to the tissues. The addition of laser makes the compound polymerize much better giving it excellent strength.

Indocyanine green dye enhanced vascular welding with the nearinfrared diode laser [8] is described in the medical literature which uses Indocyanine dye to enhance vascular welding by a nearinfrared diode laser. The dye is costly and not necessary in my technique. Collateral tissue damage due to high power laser is another disadvantage of the technique.

A costly USD 5000 infrared laser machine is necessary for this operation. I designed a cheap infrared diode laser of 5 watts power and $850 \mathrm{~nm}$ wavelength. (Figure 4). It has a laser diode, a heat sink and power supply. The machine was developed for the cost of USD 300 only. The further details of the machine are out of the scope of this article.

Glutaraldehyde is strong antiseptic, hence infection rate in group A is far less than in group B. Glutaraldehyde is hygroscopic compound, hence the Group A patients had a dry and edema free wound compared to group B. The post-operative morbidity and complication rate is far less in group A compared to group $\mathrm{B}$. Hence, group A is clearly a winner compared to group B as far as results are concerned.

Suture-less circumcision by glutaraldehyde albumin glue enhanced Laser tissue welding is a common basic learning operation for a surgeon for applying it in other areas of surgery such as for sealing post-operative wounds, CLW closure, reinforcement of suture line of bowel anastomosis, Bowel perforation, sealing dura repair, hypospadias surgery, urological operations, etc. But this article describes its use only for suture-less circumcision.

\section{Conclusion}

Suture-less circumcision by glutaraldehyde albumin glue enhanced Laser tissue welding is a safe, cheap and effective technique of performing circumcision. It is an important advance in circumcision surgery after a long time. The technique becomes a foundation for its vast application in other areas of surgery.

\section{Acknowledgements}

There are no Acknowledgements to be made about this research study.

\section{Authors' Contributions}

The first author is the inventor of the technique who has also done the clinical study. 


\section{Financial Support and Sponsorship}

The first author have done the whole research and study with his own money.

\section{Ethical Approval and Consent to Participate}

Taken and attached.

\section{Conflicts of Interest}

The authors declare no conflicts of interest regarding the publication of this paper.

\section{References}

[1] Talmor, M., Bleustein, C.B. and Poppas, D.P. (2001) Laser Tissue Welding: A Biotechnological Advance for the Future. Archives of Facial Plastic Surgery, 3, 207-213.

[2] Wadia, Y., Xie, H. and Kajitani, M. (2000) Liver Repair and Hemorrhage Control by Using Laser Soldering of Liquid Albumin in a Porcine Model. Lasers in Surgery and Medicine, 27, 319-328. https://doi.org/10.1002/1096-9101(2000)27:4<319::AID-LSM4>3.0.CO;2-G

[3] Mistry, Y.A., Natarajan, S.S. and Ahuja, S.A. (2018) Evaluation of Laser Tissue Welding and Laser-Tissue Soldering for Mucosal and Vascular Repair. Annals of Maxillofacial Surgery, 8, 35-41. https://doi.org/10.4103/ams.ams_147_17

[4] Passage, J., Jalali, H., Tam, R.K., Harrocks, S. and O’Brien, M.F. (2002) Bio-Glue Surgical Adhesive-An Appraisal of Its Indications in Cardiac Surgery. The Annals of Thoracic Surgery, 74, 432-437. https://doi.org/10.1016/S0003-4975(02)03689-5

[5] Amirghofranl, A.A., Rayatpisheh, S., Tanideh, N., Owji, A.A., Vasei, A. and Mehrabani, D. (2005) Evaluation of Different Formulations of Biological Surgical Adhesives on Hemorrhagic Aorta: An in Vitro and Animal Study. Journal of Applied Animal Research, 28, 121-124. https://doi.org/10.1080/09712119.2005.9706805

[6] McNally, K.M., Sorg, B.S. and Welch, A.J. (2000) Novel Solid Protein Solder Designs for Laser-Assisted Tissue Repair. Lasers in Surgery and Medicine, 27, 147-157. https://doi.org/10.1002/1096-9101(2000)27:2<147::AID-LSM6>3.0.CO;2-P

[7] Wolb-de Jonge, I.C., Heger, M., van Marle, J., Balm, R. and Beek, J.F. (2008) Suture-Free Laser-Assisted Vessel Repair Using $\mathrm{CO}_{2}$ Laser and Liquid Albumin Solder. Journal of Biomedical Optics, 13, Article ID: 044032. https://doi.org/10.1117/1.2953531

[8] Oz, M.C., Chuck, R.S., Johnson, J.P., Parangi, S., Bass, L.S., Nowygrod, R., et al. (1990) Indocyanine Green Dye Enhanced Vascular Welding with the Near Infrared Diode Laser. Vascular and Endovascular Surgery, 24, 564-570. https://doi.org/10.1177/153857449002400805 